\title{
Analysis of the optimum allocation of BESS for contingency support
}

\author{
J. García-Villalobos, E. Torres, P. Eguía, A. Etxegarai \\ Department of Electrical Engineering \\ E.I. Bilbao, University of the Basque Country UPV/EHU \\ Plaza Ingeniero Torres Quevedo, 148013 Bilbao (Spain) \\ Phone/Fax number: +0034 94601 7332, e-mail: esther.torresi@ehu.eus
}

\begin{abstract}
The development of energy storage technologies is considered a key issue to increase the flexibility of future power systems and to achieve high penetration levels of renewable generation. In recent years, battery-based storage has attracted great interest due to the cost reduction of lithium-ion batteries. In addition, the modularity of batteries makes possible to develop not only grid-scale energy storage facilities connected at transmission voltage levels but also smaller distributed energy storage systems connected at distribution voltage levels. However, it must be taken into account that the size and services provided by batteries depend on their location in the power system. In this paper, a methodology to determine the optimal location of battery based electrical energy storage systems for contingency support is presented. The methodology has been applied to a Spanish power system to evaluate the effect of batteries on contingency support when installed either in the transmission network or in the distribution network.
\end{abstract}

\section{Key words}

Energy storage, batteries, contingency support, PV selfconsumption, optimization

\section{Introduction}

In recent years, there has been a strong development in renewable generation, and technologies such as wind generation and photovoltaics are playing an increasingly important role in the generation mix. However, these generation technologies are non-dispatchable and so, they may lead to the appearance of overvoltages as well as stability and security issues, especially under contingency conditions. This situation may even get worse as a result of the increase in the number of distributed residential and commercial photovoltaic (PV) installations due to the limited control the network operator has over these facilities. For this reason, the development of energy storage technologies is considered essential for the secure integration of renewable generation and so, for the development of future power systems [1].

Energy storage in electric power networks has traditionally been based on pumped-storage hydroelectric power plants connected to the transmission network. However, the progressive reduction in the price of lithium-ion batteries is pushing its potential use in electric networks. Grid connected battery-based electric storage systems can provide several system services such as load management, reduction of peak demand, mitigation of overloads, integration of renewable generation, frequency and voltage control, etc. However, the ability of batteries to provide those services in an efficient way may be dependent on their size and location in the power system as, due to its modularity, battery storage systems may be connected not only to the transmission network, but also to the distribution network, or even be located at the customers' facilities [2].

According to [3], the existing literature on energy storage can be grouped in three categories: storage operation, storage sizing and storage siting. Some papers deal with storage operation, which is optimized given its energy and power ratings, as in [4]. In contrast, storage sizing involves determining the optimal size of storage at a predetermined location, such as next to a wind farm as in [5], to meet some requirements. Finally, storage siting is a more complex problem as it involves determining not only the optimal size but also the location of multiple storage units, which will depend on how they will be operated. The problem of battery siting for different applications has been analyzed in the literature. For example, in [6] batteries are applied for load peak shaving in order to defer distribution network investments, whereas in [7] batteries are applied for peak shaving and load curve smoothing so that the transmission system is relieved from the aggregate fluctuations of rooftop PV generation.

This paper proposes a new methodology that provides the optimal sizing and location of BESS for contingency support. The operation of the batteries is also optimized so that they can provide the required support during contingencies as well as load curve smoothing in scenarios with high penetration of PV self-consumption generation. The proposed methodology has been applied to the Spanish power system to evaluate the effect of the deployment of batteries either in the transmission network or in the distribution network, as an alternative to other network reinforcements. 
The paper is structured as follows. Section 2 introduces the methodology applied in the analysis, Section 3 presents the electric network used in this research and Section 4 shows the results obtained in the analysis. Finally, Section 5 presents the main conclusions of the paper.

\section{Methodology}

The proposed methodology for the analysis of the effect of the installation of batteries in the power system consists of two stages. Firstly, the optimal size and location of the batteries in the power system is determined and, after that, the charging/discharging control strategy of the batteries is considered in order to achieve their optimal operation in the power system.

\section{A. Sizing and location of BESS}

In this study, it has been considered that the main purpose of the installation of batteries is the reduction of outages. Batteries supply power to the loads during the contingency, reducing the Power Not-Guaranteed (PNG) because of the contingency. The PNG is defined as the power that cannot be supplied during the outage. A maximum available budget for the installation of batteries is considered in the methodology, so batteries to reduce the PNG during network contingencies are located at those nodes with the largest accumulated PNG to battery cost ratio, until the maximum available budget is achieved. As a battery can solve several contingencies, the rated power of the battery to be installed at a particular node of the network is equal to the maximum PNG caused by the worst contingency producing the disconnection of the node. The cost of the battery is mainly determined by its energy, and so, it is calculated taking into account the duration of the contingency. On this way, the objective function expressed by (1) is optimized, subject to the constraint of the maximum budget given by (2).

$$
\begin{aligned}
& J=\sum_{i=x}^{N} \frac{P N G R_{i}}{C b s_{i}} \\
& \sum_{i=x}^{N} C b s_{i} \leq P T
\end{aligned}
$$

where $\mathrm{N}$ is the total number of nodes that are candidates for housing a battery; $\mathrm{PNGR}_{\mathrm{i}}$ is the value of PNG avoided by the battery; $\mathrm{Cbs}_{\mathrm{i}}$ is the cost of the battery and PT is the total budget available for the installation of batteries.

\section{B. Optimization of the operation of BESS}

The evaluation of the effect of the batteries in the power system requires taking into account their charging/discharging control strategy and simulating the operation of the batteries over time.

The hourly power generated or consumed by every battery is obtained as a result of an optimization problem that is solved in hourly basis. In this research, the objective of this optimization is to obtain the operation of the batteries to improve the integration of renewable generation and electric vehicles, while providing support during contingencies. With this purpose, the operation of the batteries is optimized so that the net load curve of the network, calculated taking into account both demand and generation, is smoothed and a better use of network facilities is achieved. The optimization of the operation of the batteries is expressed as a variance optimization problem, where the variance of the net load curve is minimized, taking into account that the state of charge of the batteries must be high enough to supply the power required by the system in case of a contingency. As a result, the objective function (3) is solved for every battery, subject to the inequality constraints of the power limits of charge/discharge of the battery (4) and maximum (5) and minimum (6) state of charge.

$$
\begin{gathered}
\boldsymbol{J}=\frac{\mathbf{1}}{N} \sum_{i=0}^{N}\left[P b s_{i}+A P b s_{i}+L F_{i}\right]^{2}-\left[\frac{1}{N} \sum_{i=0}^{N} P b s_{i}+A P b s_{i}+L F_{i}\right]^{i} \\
P_{\max \__{-} d} \leq P b s \leq P_{\text {max } \_c} \\
\sum_{i=0}^{N}\left(P b s_{i}\right)+S O C_{0} \cdot Q \leq Q \\
\sum_{i=0}^{N}\left(P b s_{i}\right)+S O C_{0} \cdot Q \geq \sum_{i=0}^{M}\left(L F_{i}\right)
\end{gathered}
$$

where $\mathrm{N}$ is the number of optimization periods per day (24 periods); Pbs is the power of the battery; APbs is the sum of the power of the other batteries connected to the network; LF is the expected load supplied by the transformer; $\mathrm{P}_{\text {max }} \mathrm{c}$ and $\mathrm{P}_{\text {max_d }}$ the maximum charge and discharge power; $\mathrm{SOC}_{0}$ the initial state of charge of the battery; $Q$ the rated energy of the battery and $M$ the duration of the contingency.

\section{Network and data description}

The methodology described in Section 2 has been applied to evaluate the influence of the installation of batteries in the region of Murcia, in Spain. With that purpose, two different cases have been considered: the installation of batteries in the transmission network in large unit sizes or in the distribution network in smaller units. The location of batteries in LV distribution networks as part of customers' facilities was not considered due to the larger installation and management cost, as well as to the lack of visibility of these batteries by the network system operator.

The network model used in the study includes the MV distribution network of Murcia and the entire HV Spanish transmission network, as shown in Figure 1. The HV network $(>20 \mathrm{kV}$ ) covers the whole Spanish transmission and sub-transmission networks and their interconnections with Portugal, France and Morocco. The MV network comprises the whole distribution network (from $1 \mathrm{kV}$ to $20 \mathrm{kV}$ ) of the region of Murcia (Figure 2) and is composed of 90 radial feeders. The MV network has a 
meshed layout but it is radially operated, as represented in Figure 2. Table 1 shows the number of the different elements included in each network.

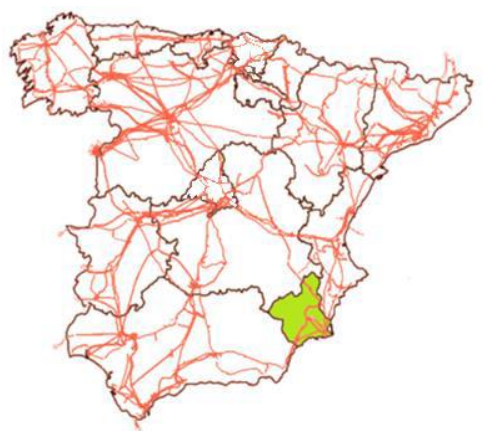

Fig. 1. HV electric transmission network, with the region of Murcia in green colour

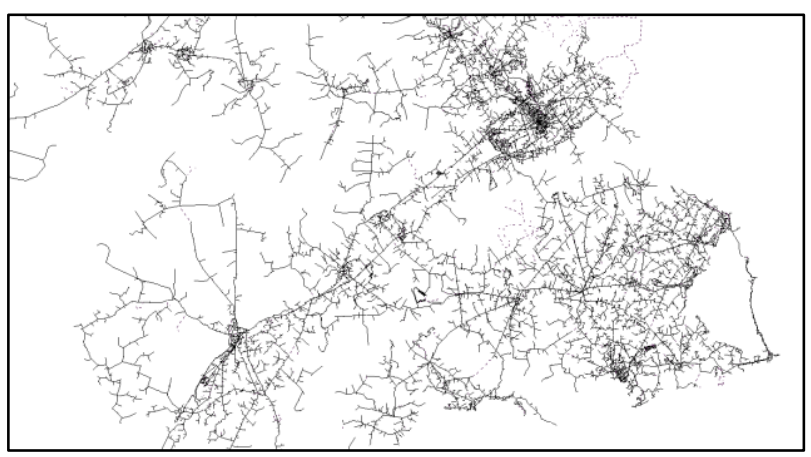

Fig. 2. MV distribution network of Murcia

Table I. - Number of HV and MV network elements

\begin{tabular}{|c|c|c|c|c|c|c|}
\cline { 2 - 7 } \multicolumn{1}{c|}{} & Areas & Nodes & Generators & Loads & Transf. & Lines \\
\hline HV network & 1 & 2674 & 655 & 989 & 1243 & 3788 \\
\hline MV network & 90 & 31721 & 15388 & 15388 & 94 & 33327 \\
\hline
\end{tabular}

To build the base case, real consumption data of Murcia during 2014 has been considered in this study. This data consists of eight different days (one working day and one weekend day for each season) characterizing the whole year and whose load curves are represented in Figure 3.

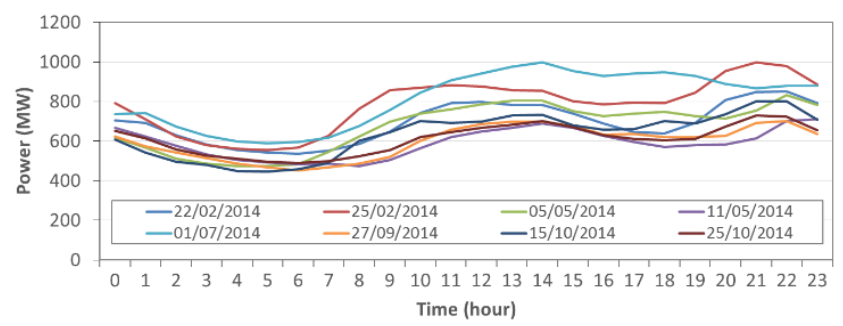

Fig. 3. Daily load curves of Murcia

From the base case, a future scenario corresponding to the year 2025 has been built, with greater demand and penetration level of renewable generation than the base case, so that the benefits from the installation of electrical storage in the electric networks can be identified. In this future scenario, the effect of the installation of batteries either in the transmission and distribution networks has been analyzed.
In the 2025 scenario, an increase of $1.7 \%$ in the load demand per year, as considered by REE in [8], has been considered. The load demand in the scenario 2025 includes also the demand of electric vehicles, which has been estimated from the results of a study from Deloitte and presented in [9]. Finally, the scenario 2025 considers also a greater penetration of renewable energy, mainly due to the development of PV self-consumption. In particular, a $20 \%$ penetration level of PV selfconsumption, slightly concentrated in rural areas, has been adopted. The methodology applied to locate PV self-consumption installations in the distribution network is described in [10]. Table II shows the demand and generation corresponding to the winter peak and the summer peak of the base case and the future scenario.

Table II. - Demand and generation in the base case and the

\begin{tabular}{|c|c|c|c|c|}
\multicolumn{2}{c}{ future scenario } \\
\cline { 2 - 5 } \multicolumn{2}{c|}{ Load (MW) } & \multicolumn{2}{c|}{2014} & \multicolumn{2}{c|}{2025} \\
\hline peakter & $\begin{array}{c}\text { Summer } \\
\text { peak }\end{array}$ & $\begin{array}{c}\text { Winter } \\
\text { peak }\end{array}$ & $\begin{array}{c}\text { Summer } \\
\text { peak }\end{array}$ \\
\hline Customers & 992 & 994 & 1172 & 1185 \\
\hline Electric vehicle & 0 & 0 & 18 & 4 \\
\hline Total load MV & 992 & 994 & 1190 & 1188 \\
\hline Distributed generation & 235 & 294 & 235 & 294 \\
\hline PV self-consumption & 0 & 0 & 0 & 468 \\
\hline Total generation MV & 235 & 294 & 235 & 762 \\
\hline
\end{tabular}

\section{Study results}

In this research, the main objective of the installation of batteries is that they can provide support during contingencies and improve the quality of supply. So, a contingency analysis was firstly carried out in the transmission and distribution networks of Murcia.

In the distribution network, a topological analysis is applied so, in the case of consecutive nodes, only the failure at the head node is considered. In addition, the possibility of reconfiguration of the distribution network is also taken into account in order to reduce the PNG. As a result of the contingency analysis in the MV distribution network, $529 \mathrm{~N}-1$ contingencies were identified in the situation corresponding to the winter peak, producing a total PNG of 354.9 MW. In contrast, $418 \mathrm{~N}-1$ contingencies were obtained in the summer peak, leading to $285.5 \mathrm{MW}$ of PNG.

In the transmission system, the worst situation identified because of the contingency analysis is a $\mathrm{N}-2$ contingency produced in a coastal $220 \mathrm{kV}$ transmission line of Murcia. The $220 \mathrm{kV}$ system in Murcia becomes supplied from the $66 \mathrm{kV}$ network, causing voltage collapse and the loss of several substations. This situation can be mitigated by means of load shedding; being the load affected in Murcia equal to 51.6 MW of PNG in the winter-peak and 44.4 MW in the summer-peak.

The average duration of contingencies during which batteries must provide support has been considered to be 3 hours for contingencies in overhead distribution lines and 9 hours for failures in underground distribution lines 
and overhead transmission lines. According to [11], the cost of the batteries differs depending on the application. In this study, the following values have been considered:

- Contingency support in overhead distribution line (power/energy 1:3): 232.6€/kWh

- Contingency support in underground distribution line (power/energy: 1:9): $212.4 € / \mathrm{kWh}$

- Contingency support in overhead transmission line (power/energy: 1:9): $212.4 € / \mathrm{kWh}$

From the results obtained in the contingency analysis and by means of the application of the methodology described in Section 2, taking into account an accumulated budget of 100 Mill. $€$ for the purchase of batteries in 2025, two different optimal sets of batteries have been estimated for installation in the transmission and distribution networks of Murcia, respectively:

- 63 batteries in the MV distribution network with a total power of $76.5 \mathrm{MW}$, a total energy of 433.5 MWh and a total cost of 99.81 Mill. $€$.

- 2 batteries in the HV transmission network with a total power of $52 \mathrm{MW}$, a total energy of 468 MWh and a total cost of 99.4 Mill. $€$.

The batteries calculated have the most effective size and location that allows reducing the PNG with the minimum cost, taking into account all the possible contingencies. In the case of installation of batteries in the distribution network, priority has been given to those batteries that solve not only distribution contingencies but also contingencies in the transmission network.

To compare the influence of both sets of batteries on the performance of the power system of Murcia, the charging/discharging of the batteries has been simulated over a full year by means of solving an optimization problem every hour, which allows determining the hourly power generated/consumed by each battery. The operation of the batteries in the transmission network is optimized so that the load curve of the distribution network is smoothed and a better use of distribution network facilities is achieved. In the same way, the objective of the batteries in the distribution network is the smoothing of the load curve of HV/MV distribution transformers, which has a positive effect on their lifetime. In the simulation, an efficiency of 93.8\% has been considered in the charging and discharging of the batteries, which means a net efficiency equal to $88 \%$.

Figure 4 presents an example of the behavior of one of the batteries located in the distribution network, as a result of the strategy adopted for the operation of the batteries. As it is shown, the battery stores excess PV generation during the day which is returned at night. It can be observed that the battery does not discharge completely but it keeps a state of charge that allows supplying the energy required in case of a contingency. The state of charge of the battery is kept between a maximum and a minimum limit. The maximum SOC limit is equal to unity, since the battery cannot be charged above its maximum capacity. In contrast, the minimum SOC limit represents the minimum load level necessary to cope with the contingency.

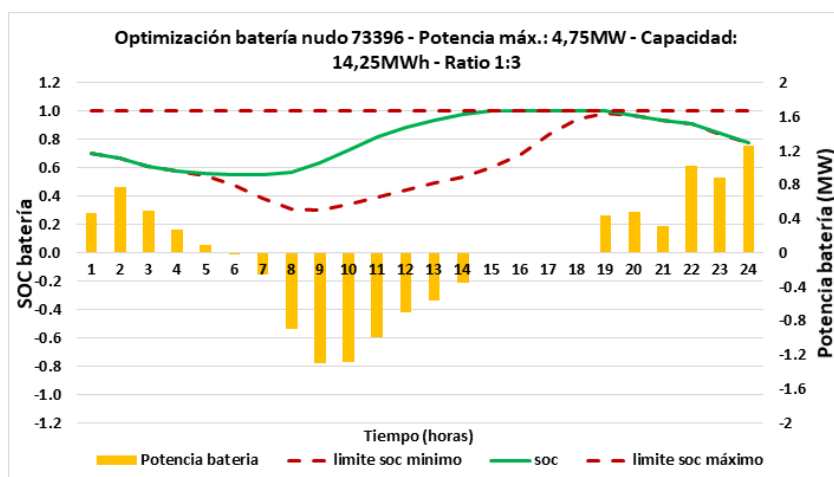

Fig. 4. Effect of battery dispatch on the operation of one battery in the area of S.Felix in Murcia

As a result of the optimization of the operation of all the batteries installed in the same distribution feeder, the load curve of the transformer supplying the feeder is smoothed in comparison with the situation without batteries (Figure $5)$.

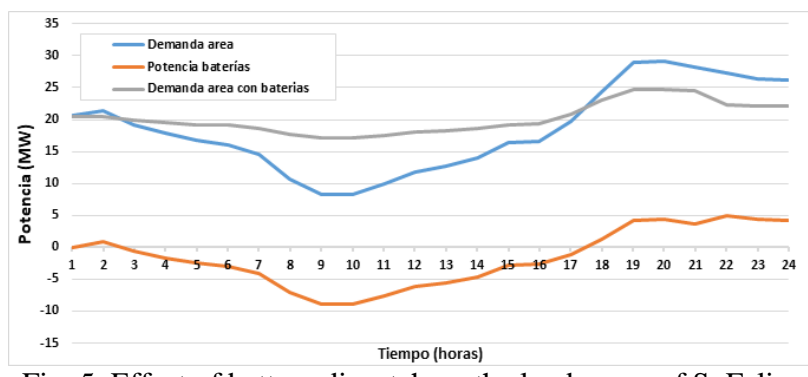

Fig. 5. Effect of battery dispatch on the load curve of S. Felix transformer in Murcia

The simulation of the operation of the batteries allows analyzing their effect on electrical magnitudes, such as voltage and power losses, as well as evaluating their influence in the integration of renewable generation. In the next sections, the influence of BESS on different magnitudes, obtained as a result of this research, is shown.

Both the calculation of the load flow and the subsequent analysis of the data have been automated using Python scripts, for PSS/E, and VBA macros, for Excel. In addition, the IBM ILOG CPLEX optimization software in the Python environment has been used for the planning and resolution of the battery operation optimization problem.

\section{A. Influence of BESS on network contingencies}

The contingency analysis of the power system of Murcia under the scenario 2025 with both optimal sets of batteries allows evaluating the influence of their location in the power system on contingency management.

In the case of batteries in the distribution network, 460 $\mathrm{N}-1$ contingencies with a PNG of $251.8 \mathrm{MW}$, are obtained for the winter-peak, and $386 \mathrm{~N}-1$ contingencies with a PNG value of 234.1 MW, for the summer-peak. On this way, the deployment of batteries in the distribution network has a positive effect as it reduces the number of outages as well as the global PNG, in comparison with the situation without batteries. Taking 
into account whether the failure happens in the transmission or in the distribution network, the effect of the batteries in comparison with the situation without batteries can be estimated also in terms of the Energy NotSupplied (ENS):

- Decrease of 103.1 MW in PNG and of 897.8 MWh in ENS for the winter-peak

- Decrease of 51.9 MW in PNG and of 448.2 MWh in ENS for the summer-peak

The location of batteries in the distribution network has also a positive influence on transmission contingency management:

- $\quad$ Decrease of 8.3 MW in PNG and of 74.7 MWh in ENS for both the winter and summer peaks.

In contrast, if the batteries are located in the transmission network, no improvement is obtained for contingencies in the distribution network and only contingencies in the transmission network are solved:

- $\quad$ Decrease of 51.6 MW in PNG and of 464.4 MWh in ENS for the winter-peak

- Decrease of 44.4 MW in PNG and of 399.6 MWh in ENS for the summer-peak

It can be concluded from these results, that the effectiveness of batteries in case of contingencies is much higher if they are located in the distribution level since they provide a greater PNG reduction for contingencies in the distribution network as well as additional support for contingencies in the transmission network. However, the location of batteries in the transmission network solve only transmission contingencies, without providing support against distribution contingencies.

\section{B. Influence of BESS on system voltages}

The installation of batteries can influence the voltage profile. To analyze their effect on voltage, two battery control strategies have been considered in the simulation: batteries without voltage control, injecting or absorbing only active power; and batteries with voltage control at the node the battery is connected to with a power factor of \pm 0.9 . Figures 6 and 7 show the range of variation of voltage values obtained in each case in the nodes of the distribution feeders with the greatest installed power in batteries when located in the MV distribution network and closest to the area of influence of batteries when located in the transmission network. Percentiles 5, 50 and 95 of hourly voltage values are represented and compared with the maximum and minimum voltage values of $\pm 7 \%$ allowed in the distribution network. It is observed that the installation of batteries in the distribution network increases the lower voltage level in comparison with the situation without batteries and that the influence is more noticeable when batteries with voltage control are considered. In contrast, the installation of fewer batteries with higher power in the transmission network has a negligible effect on the voltage values obtained in the distribution network, as their influence on voltage is limited to a more reduced area of the power system.

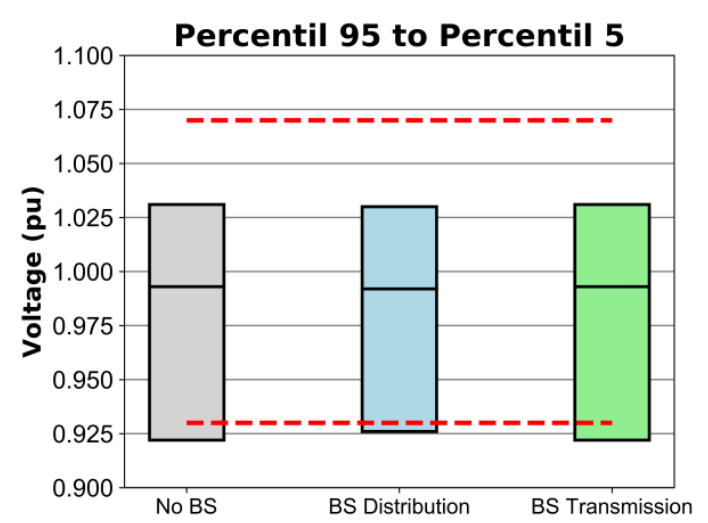

Fig. 6. Voltage values with BESS without voltage control

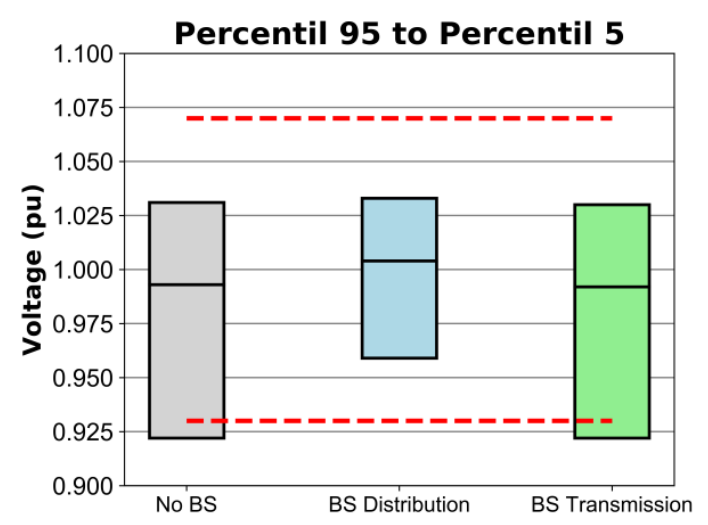

Fig. 7. Voltage values with BESS with voltage control

\section{Influence of BESS on power losses}

It has been obtained from the simulation that the effect of the installation of batteries on network losses is not significant due to the low value of power installed in batteries in comparison with demand. In principle, batteries reduce network losses in comparison with the situation without batteries, due to the load curve optimization carried out by the batteries, as shown in Figure 8. The reduction is larger for batteries in distribution as in that case batteries reduce the variance of the load curve of the HV/MV transformer supplying the feeder where batteries are installed, whereas in the case of batteries in transmission they optimize the load curve of the whole region.

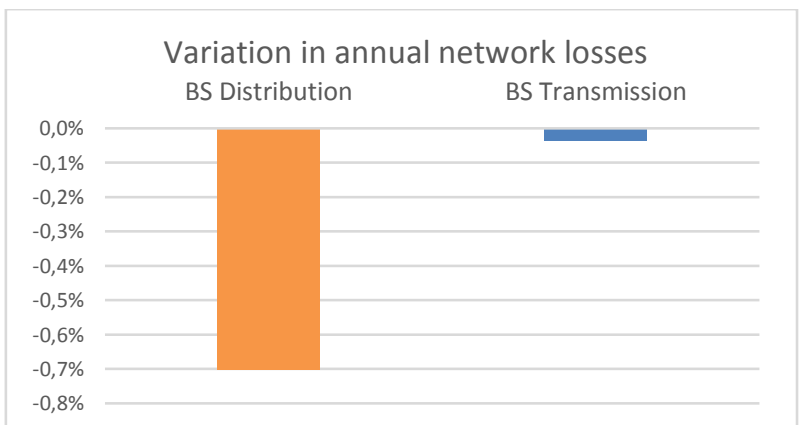

Fig. 8. Influence of BESS on the variation of annual network

On the other hand, if battery losses are included, then total losses increase, as represented in Figure 9. However, as depicted in Figure 10, the ratio of the reduction in network losses to battery losses becomes larger for batteries in distribution than for batteries in 
transmission, which means that the installation of batteries in the MV distribution may be more efficient to reduce losses if their efficiency is improved, than the installation of batteries in the transmission network. The efficiency of batteries to reduce losses may be even improved if they are operated to develop voltage control.

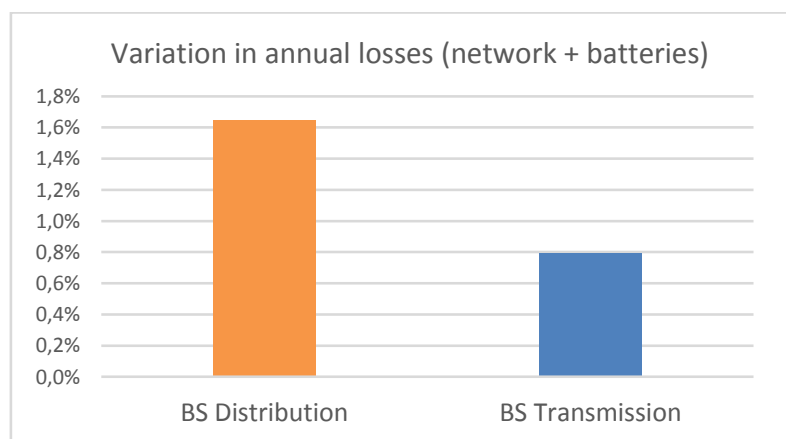

Fig. 9. Influence of BESS on the variation of annual total losses

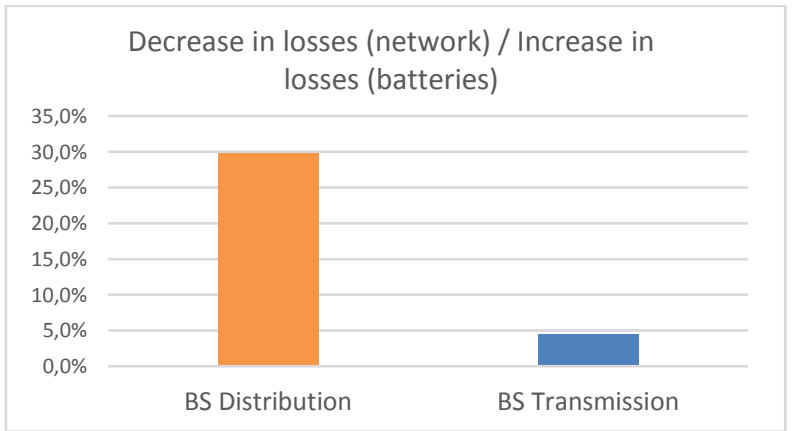

Fig. 10. Ratio of saved annual network losses and annual battery losses

\section{Conclusion}

It is widely accepted that the application of BESS in the power system can provide multiple system services. However, the optimal size and location of batteries is strongly influenced by how the batteries will be operated. In addition, the efficiency of the batteries in the provision of system services may depend on their size and location within the power system so it may be questioned whether an optimal location exists that maximizes the profit for the power system. In this paper, a methodology has been proposed for the determination of the optimal size and location of batteries in the power system in order to provide support during network contingencies. This methodology has been applied to the actual electric network of Murcia, in Spain, in order to evaluate the benefits of the installation of BESS in transmission and distribution. The results of the analysis have shown that the installation of batteries in the distribution network provides a better solution in case of contingency, as they can be located to mitigate not only distribution contingencies but also to provide support in case of contingencies in the transmission network. In contrast, it has been obtained that the allocation of batteries in the transmission network provide only very limited support to distribution contingencies leading to loss of load. The deployment of batteries in the distribution network has shown also to have a better performance in comparison to the allocation of batteries in transmission, as they improve the network voltage profile and the affection to electricity losses is lower.

\section{Acknowledgement}

This research was supported by "Energía y Sociedad" dissemination platform, the Basque Government (Ref. IT 1083-16) and the University of the Basque Country UPV/EHU (Ref. PPG 17/23). Additionally, authors would like to thank Iberdrola Company for all data provided for the application case.

\section{References}

[1] IRENA, "Electricity storage and renewable: costs and markets to 2030", October 2016. [Online]. Available: http://www.irena.org/-

/media/Files/IRENA/Agency/Publication/2017/Oct/IREN A_Electricity_Storage_Costs_2017.pdf

[2] G. Fitzgerald, J. Mandel, J. Morris, H. Touati, "The economics of battery energy storage", 2015. [Online] Available: https://www.rmi.org/wp-content/uploads/2017 /03/RMI-TheEconomicsOfBatteryEnergyStorageFullReport-FINAL.pdf

[2] H. Pandžić, Y. Wang, T. Qiu, Y. Dvorkin, D.S. Kirschen, "Near-Optimal Method for Siting and Sizing of Distributed Storage in a Transmission Network", IEEE Transactions on Power Systems, Vol. 30(5), pp.22882300, September 2015.

[3] E. Reihani, M. Motalleb, R. Ghorbani, L.S. Saoud, "Load peak shaving and power smoothing of a distribution grid with high renewable energy penetration", Renewable Energy, Vol. 86, pp. 1372-1379, 2016.

[4] Y. Zhang, S. Zhu, A.A. Chowdhury, "Reliability Modeling and Control Schemes of Composite Energy Storage and Wind Generation System With Adequate Transmission Upgrades", IEEE Transaction on Sustainable Energy, Vol. 2(4), pp. 520-526, October 2011.

[5] S.R. Deeba, R. Sharma, T.K. Saha, D. Chakraborty, A. Thomas, "Evaluation of technical and financial benefits of battery-based energy storage systems in distribution networks", IET Renewable Power Generation, Vol. 10(8), pp. 1149-1160, 2016.

[6] Y. Yang, H. Li, A. Aichhorn, J. Zheng, M. Greenleaf, "Sizing strategy of distributed battery storage system with high penetration of photovoltaic for voltage regulation and peak load shaving", IEEE Transactions on Smart Grid, Vol. 5(2), pp. 982-991, March 2014.

[7] Ministerio de Industria, Energía y Turismo, "Planificación Energética. Plan de Desarrollo de la Red de Transporte de Energía Eléctrica 2015-2020". [Online]. Available: http://www.minetad.gob.es/energia/planificacion/Planifica cionelectricidadygas/desarrollo20152020/Paginas/desarrollo.aspx

[8] Deloitte, "Un modelo de transporte descarbonizado para España en 2050. Recomendaciones para la transición", Marzo 2017. [Online]. Available: https://www2.deloitte.com/es/es/pages/strategy/articles/me didas-descarbonizacion-transporte.html

[9] P. Eguía, E. Torres, J. García-Villalobos, "GEDISPER Distributed generation impacts on power losses", 2016. [Online]. Available: http://www.energiaysociedad.es/wpcontent/uploads/2016/11/Final-Report-GEDISPER-ENversion-v0.compressed.pdf

[10] Lazard, "Lazard's Levelized Cost of Storage - Version 2.0", December 2016. [Online]. Available: https://www.lazard.com/media/438042/lazard-levelizedcost-of-storage-v20.pdf 